\title{
An Analysis of Destination Attributes for Attracting International Millennial to Kandy City
}

\author{
Rangana Sri Shalika Wadippuli Arachchi
}

Sabaragamuwa University of Sri Lanka

\begin{abstract}
The purpose of this study is to identify important destination attributes of Kandy city and examine how and to what extent those attributes impact on international tourists' decision on choosing their destination. A proposed model was formulated and it postulates that international tourists' perception of Kandy City important attributes that impacts on their decision making in three ways: (1) directly; (2) it influences on the overall image of Kandy city, and in turn, influences their decision; (3) it also impacts on the international tourists' overall satisfaction with their trip to Kandy city, and in turn, influences their own or their peripheral people future decision on destination selection. Destination attributes were identified based on a triangulation approach prior to the research. A structured questionnaire was used to collect the data. One hundred and sixty (160) international tourists (millennial) were selected as the sample. In addition, 15 millennial tourists were interviewed to prove the findings of survey further. The valid data collected was computed by means of the SPSS to gain basic frequency statistics. The results also showed that, the Kandy city attributes revealed different importance levels in influencing tourists' destination decision making, formation of Kandy city overall image, and the tourists' satisfaction.
\end{abstract}

Keywords: Destination attributes, Millennial, Attraction, Kandy

\section{Introduction}

The context of Millennial is a global phenomenon. It involves the movement of millions of millennial travelers around the world and refers to a diverse range of experiences and activities that can include work, volunteering, education, leisure and holidaying. Hence most of the world major tourism players such as Australia, NewZealand, India and other Europe countries have implemented many development plans with the purpose of gaining more economical advantages through millennial. But many researches and other scholar articles have produced on the basis of international tourists whereas it's lacking of millennial tourism with their expectations within a traveling destination. Sri Lanka has superior and unique tourism value based on its social, natural cultural and economic uniqueness with the richest environmental attributes. Being a compact island, these resources distribute all over the country. As a result of that, Sri Lanka is become one of most famous tourist destinations among tourists. According to the SLTDA annual report (2015), India became the major tourist generator while China, UK, Maldives, Germany, Australia, France, UK, Russia, USA and Japan contributed respectively. Sri Lanka's aim is to achieve 2.5 million tourist arrivals with the end of 2020. As the Sri Lanka's tourism statistics, according to the Sri Lanka Tourism Development Authority (2018), arrivals of tourists to Sri Lanka in 2018 have been risen $14 \%$ from the year 2017. Due to the rise of the relevant arrivals, tourism was able to upgrade its rank to the third level as the largest source of Foreign Exchange Earner of the national economy in 2018.

The tourists, who travel with the purpose of the pleasure and visiting friends and relations, as it is found by the statistics, play a major role in Sri Lanka tourism industry. From the nature of this both categories, as well as with the tendency of travelling for pleasure, it always implies to the researcher that the most of the tourists may be 'back packers', 'mini back packers', 'generation Y travelers' as well as most of them are the millennial. However, the consideration of age levels of travelers when taking trips to Sri Lanka, its being clearly illustrated by SLTDA (Sri Lanka Tourism Development Authority) tourism statistics as follows. Those illustrations would show which age groups are the most important contribution to be given for the industry. 


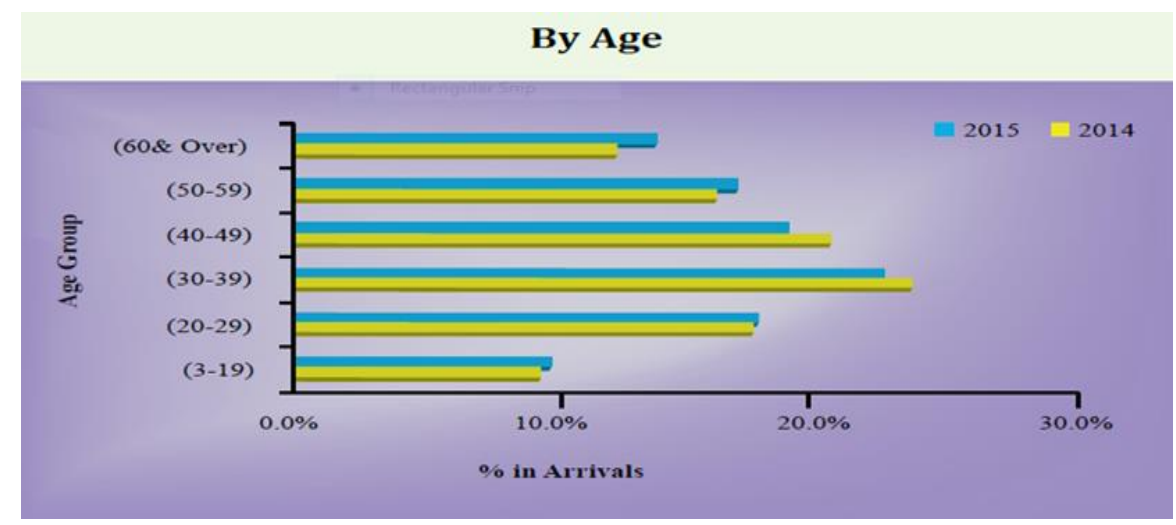

Figure 1.1: Tourist Arrival by Age

Source: Annual Report SLTDA (2015)

Millennial, the term stands for the generation who are born between early 1980s \& early 2000. Perhaps the most commonly used birth range for this group is 1982-2000. The millennials, the travelers who are in age level between 17-38 years old; the generation is also known as Generation Y, because it comes after Generation X; those people between the early 1960s and the 1980s. Millennials are found with different characteristics. Their travel expectations are also may differ. Figure 1 is the illustration of tourist arrival by age to Sri Lanka in the years of 2014 and 2015. As it shows the mostly arrived age group is 30-39. As well as the third important age group is 20-29. Nearly those both age groups can be identified in one single group as 20-39. It is the result of tourist arrivals by age to Kandy city also. Comparing to other tourist attractions in Sri Lanka, Kandy has been attracted by Millennial. Therefore, Kandy has been selected as the research site for the study. Kandy, the last royal capital of Sri Lanka is a major tourist destination, which is $115 \mathrm{KM}$ away from Colombo and is located at 465 meters above the sea level. The city is most famous for the Temple of Tooth relic and many other temples and attractions. The city could be called the cultural capital of the island. Kandy is a good transit position point to the cultural triangle to the north or hill country on the way to the south of the country. The city plays a role for good source of souvenirs or to witness many cultural performances at its various hotels in the city. Kandy is the home to the Sri Temple of tooth relic - the beautiful temple that houses the tooth relic of Lord Buddha - Kandy is also a popular stop during July/August when the annual Esala procession, the holy festival takes to the streets of the city. The cool climate of the hills is a relief after the cloying heat of the lowlands, and the lovely Kandy Lake and the drives around it are set amidst great scenic beauty.

According to the Cloud Buster Marketing Consultancy Institute-Canada (2016), the millennial travelers are going to be enriched with more extra income on their hands to spending on travels due to living at their parents' homes for longer. They have planned their discretionary income to make trips living separate instead. It stated that the millennial income is slated for growing over the next coming decade, surpassing boomers and generation $\mathrm{X}$ by 2025 due to the projection of millennial households. 


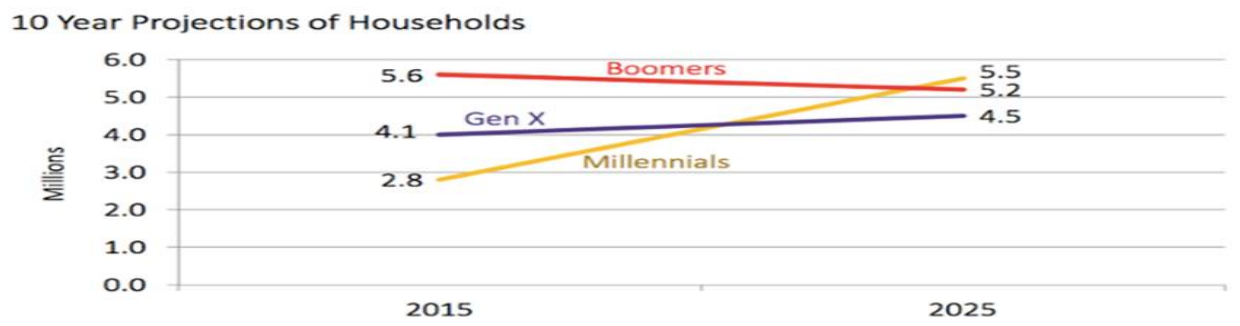

Figure 1.2: projection of households in Canada in next decade Source: http://www.cloudburstmarketing.ca (2016)

With this statistical data, it shows that the importance of addressing the strategic marketing trends for the millennial segment in the tourism industry in near future. As the data shown in the figure "The trip number of international millennial travelers is expected to nearly double by 2020 ". As it says the millennial trip number doubles, the hospitality partners are warned to be ready so that it provides the services to fulfill the countries hospitality deficiency.

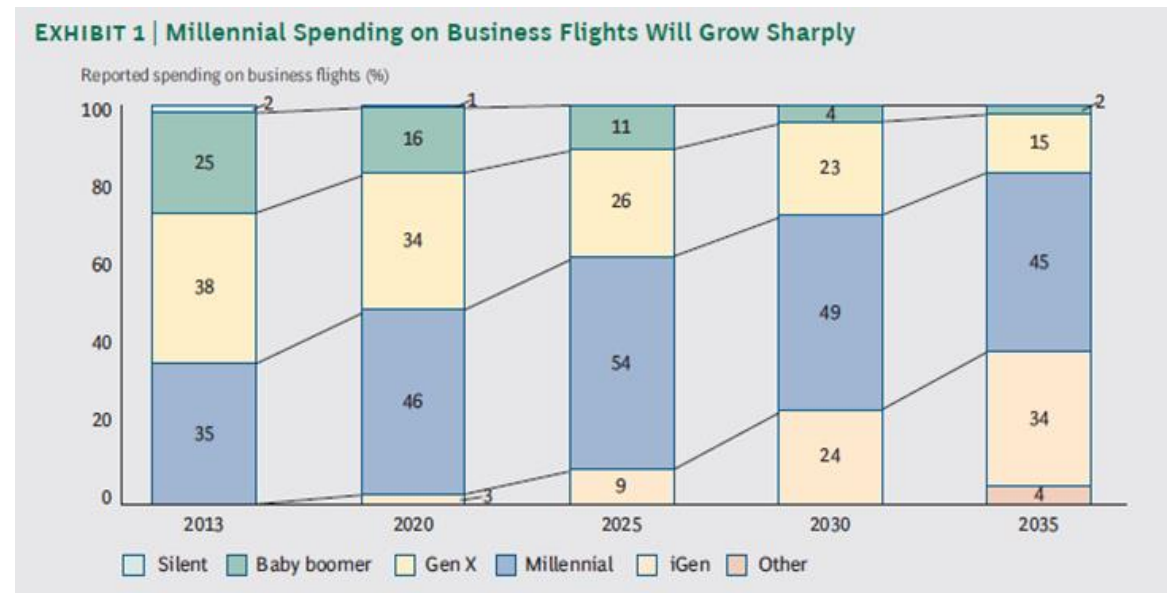

Figure 1.3: Behaviour of U.S. millennials spending on business flights Source: Boston consultancy group report (2013)

As it shows in the above figure 1.3, the survey by the Boston consultancy group of taking business flights by the U.S millennial, it shows a sharp increase of taking business flights by millennial by 2035 and a decrease of all other generations' amount of taking business flights namely baby boomers, generation X. These implications and the booming importance were the most inspiring aspects for the researcher to consider "millennial" in this research study.

\section{2. Research questions}

- What are the major destination attributes of selecting Kandy city as the visiting destination by millennial?

- What are the most important destination attributes of Kandy city, according to the international millennial satisfaction level?

\subsection{Objectives of the Study}

- To identify the major destination attributes of selecting Kandy city as the visiting destination by millennial

- To identify the most important destination attributes of Kandy city, according to the international millennial satisfaction level

\section{4. Significance of the Study}

Tourism has become one of the fastest growing industries since recent decades and been a great instrument to achieve the regional development. Through uplifting the tourism industry, it paves the ways to trigger new 
economic activities in the country. From the insights going to be discussed through this study is importance for several parties such as government and policy makers, tourism professionals and managers, entrepreneurs and future researchers. As most of the previous studies on destination attractiveness and attributes, are based on travelers' interests who are from the world. Discovering the tourists' motivations for traveling and the destination attributes which pull tourists to the destination are covered in research studies. Even the most of research studies, the world travelers as international travelers were mostly interviewed for their further information. This study fills the gaps by focusing on destination attributes and the modern category of tourists, 'the Millennial' as the target interviewing group.

\section{Literature Review}

Dann (1977) stated that a destination's attributes are considerable as the 'pull factors of the destination'. In accordance with Dann's theory, (1977: 185), the pull factors of the destination, can draw someone to a specific destination. In other way, the 'pull factors' can lead a person or a traveler to select one destination over another hundreds of destinations comparing with. The 'pull factors' may be referred as exogenous factors, which have been characterized as the features of attractions, or attributes of a travel destination (Klenosky, 2002: 385). Dann has also examined the endogenous factors, which he referred as 'push factors of the traveler'. The 'push factors' are reviewed as the wants and needs of a tourist, such as escape from their familiar home environment, selfrelaxing, nostalgia, being calm and rest, prestige, skills and knowledge, witnessing, and social interaction. Dann's 'push-pull theory provides a simple approach for understanding about tourists' motivation factors for traveling, and explaining why a particular tourist tend to select one destination over another several or number of destinations.

\section{1. Destination attributes}

Price is a major concern in a tourist's decision to select one destination over other destinations. The price in the destination, itself doesn't mean to tourists. Only when the price is associated with a particular destination, or a specific tourism based product and their corresponding services quality becomes an important attribute for the tourists' buying selection or consideration. According to Gooroochurn and Sugiyarto (2003: 4) they argued that the price competitiveness of the destination is usually concerned as one of the most vital attributes for a given destination. In past decades, some researchers (Miller, 1997; Richards, 2001; Smith, 2003) argue that the cultural attractions in destination are the most important and considerable attribute, which motivates the people to travel. According to Rojek (1997) and Shenkar (2001) they explain that the growth of cultural tourism is faster due to two reasons. First, the increasing tourism has been boosted due to increase of disposable income in general, and in return it has boosted the cultural tourism as well. Second, increasing the levels of education of people have also stimulated the demand for the major cultural tourism in practice.

In a destination, its "entertainment attribute" could be found in many ways and forms, such as activities done outdoor, nightlife and gambling. Tourists enjoy the attributes of entertainment during their visit in a destination (Khirun, 2011). A survey which was done by Richard (2002: 1055) discovered that $46 \%$ of feedbacks were interested in entertainment when they were in a visit even a cultural site. Entertainment is become an essential part of its attributes of tourist destinations (Formica, 2000: 37).

When tourism has become a mass industry due to a number of travelers started to enjoy travel, tourism was defined as an "industry of landscape", and it is fully integrated with environment of destination (Formica, 2000: 2). Tourists, when they are especially in holiday mood, they would like to enjoy natural views and scenic beauty within the destination. Both weather and climate may significantly influence activities of tourists and their behaviors, just like they influence people's routine life style as well. Climate and weather can be the attractions in their decisive role on their destination selection. When tourists think about purchasing a tourism product, they 
ponder about its different attributes, such as services, price, entertainment, and beauty. The climate as well as the weather is also evaluated in this phase, as they could be seen as form a part of the main product (Martin, 2005: 578). Tourists' destinations selection is mostly influenced by convenience. Within given choices among similar destinations with accessibility, the tourists tend to select more convenient one as their travel destination. Thus, destinations, which are more approximate, would be more likely to be access over the destinations which are offered similar services and products (McKercher, 1998: 39). The accessibility for a particular destination is decided by a wide range of influences. Many of them might depend on much broader concerns like, social, economic or political, such as the rules and regulations of the airline industry, visa processes and permits, hubs, route connections, port capacities, landing slots and the competition among carriers (Crouch \& Ritchie, 1999: 149).

\subsection{Millennials}

Millennial (also known as Generation Y) are the demographic cohort following Generation X. There are no precise dates for when this cohort starts or ends; demographers and researchers typically use the early 1980s as starting birth years and the mid-1990s to early 2000s as ending birth years. Millennial are a very large generation, the second largest in US history, only smaller than the baby boomers (born 1946 -1964) (Hu \& Ritchie, 1993). More than half of the Millennial are already voting age adults. Many Millennial are already in graduate schools or into careers. Millennial expect a much greater array of product and service selectivity. They have grown up with a huge array of choices and they believe that such abundance is their birthright. This is a sea change in consumer behavior. Millennial also feel less need to conform in their consumer choices to everyone else in their generation or to other generations.

\section{Methodology}

\subsection{Research Design}

Research design provides a framework for the data collection and data analysis. A choice of research design reflects decisions about the priority being given to a range of dimensions of the research process. There are five main types of research designs: Experimental design, cross-sectional or survey design, longitudinal design, case study design, and comparative design. There are also three major research design approaches; exploratory, descriptive and explanatory. The descriptive research design is the most appropriate research design for studies addressing a subject about which there are high levels of uncertainty and ignorance about the subject. To achieve the objectives of this study, it was used the descriptive research design by the researcher to achieve the objectives of the study since it provides insights to the understanding of the research problem. According to the study objectives, this study is based on empirical setting to investigate the theoretical introductions drawn from the literature and tests the validity. Quantitative techniques can measure specific characteristics through structured data collection procedures from a larger representative sample, so that the result can be projected to the entire population (Davis, 2000). The main strength of the quantitative research approach is to provide a concise answer to the research question through acquisition and analysis of information that can be aggregated from the survey data. The study incorporates both quantitative and qualitative triangulation of data where empirical findings show the level of significance of the relationship and qualitative information explores interpretation of the phenomena.

\subsubsection{Population and Sample}

The population refers to "the entire group of people, events, or things of interest that the researcher wishes to investigate" (Sekaran \& Bougie, 2011). The purpose of this study is to generate a proper understanding of the inherited importance of Kandy city's destination attributes. The contribution of the research study would be helpful for the tourism, socio, economic development in central Province Sri Lanka. Thus, the population for this study was consisted with a major group called 'Millennial travelers in Kandy city. The number of respondents of the sample was decided based on the sample size determination table developed by Krejcie and Morgan (1970). Sampling frame is the collection of all millennial tourists visit Kandy city. Even though the positivistic researcher 
generally forced to follow the probabilistic sampling there may be several occasions where researcher cannot rely on it (Kothari, 2007). The researcher used the convenience sampling technique in questionnaire survey as nonprobability sampling method. Further Purposive sampling technique was used in selecting tourists for interviews.

Sample is a sub set of population where the researcher draws conclusions and generalize the conclusion to the population of interest (Sekaran \& Bougie, 2011). According to the purpose of this study, among the study population, sample of 150 was selected to get data for the study. In addition, fifteen face to face interviews were conducted with millennial respondents to enhance the validity of the findings.

\subsubsection{Types of data, data collection and analysis}

Primary data were collected through the survey conducted with the sample. A structured questionnaire was used to collect the information regarding from millennial tourists to investigate their preferences and less attractive city attributes in Kandy city. As this study refers to mix method of the combination of qualitative and quantitative phases, the researcher tends to hold a round of interviews to reconfirm the research findings thoroughly as it is. Data collection tools refer the instruments used of collecting data. For the purpose of collecting primary data, the researcher has used structured questionnaire and structured interviews. The data were collected through a survey research to get information from the selected sample. The survey was conducted through a structured selfadministrated questionnaire presented to the selected sample. The questionnaire prepared for the purpose of collecting primary data was consisted with two sections. The first section designed to gather demographic information of tourists and second part of the questionnaire was addressed the city attributes' effects and attractiveness of them. Thereby 10 city attribute effects were measured using three equal questions per each dimension. These attributes were identified through previous research literature. They are Landscape \& scenic beauty, Cultural \& history, Entertainment, Services, Accessibility, Safety, Relaxation, Climate, Price, Night life.

Further, qualitative data were collected with face-to-face comprehensive interviews. The data collected from the designed questionnaires were processed and analyzed by using very formal research analyzing and presentation methods. The analysis was supported by using the package SPSS and MS Excel software packages. Mean and Standard Deviation were calculated to rank the destination attributes and identify the most important attribute.

\section{Data analysis}

\subsection{Descriptive Statistics Analysis}

A total number of one hundred and sixty (160) questionnaires were distributed and collected from international millennial tourists. Out of them, 150 questionnaires were valid, representing 93.75 percent of the total. The invalid amount is ten (10), representing 6.25 percent of the total. The valid data was computed and analyzed with the assistance of the SPSS version 21.0 for Windows, in terms of certain statistical methods. The results given by the SPSS, were further justified by fifteen (15) interviews obtained from international millennial tourists who were at the Kandy city area. 


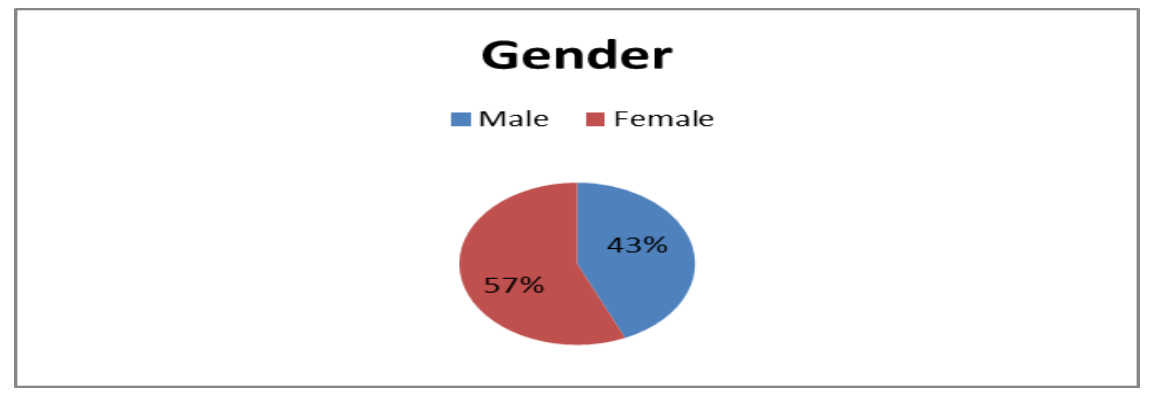

Figure 4.1: Gender Distribution

Source: Survey data (2018)

At the questionnaire distribution, the researcher experienced the possibility of distributing the questionnaires to small female groups travel together than male or mixed (male+female) groups. As well as the majority of this small groups could be identified as backpacker millennial tourists.

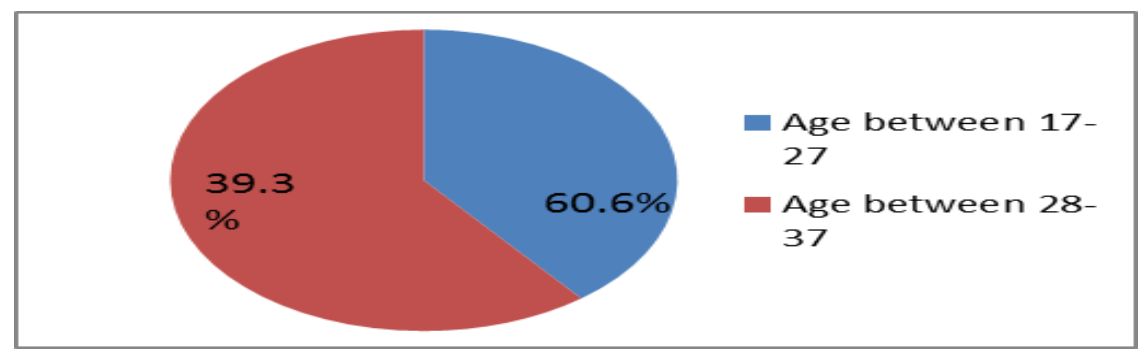

Figure 4.2: Age distribution

Source: Survey data (2018)

The researcher tried to categorize all millennial in to two groups for the explanation easiness and to discover a specific point of their arrival amount in terms of elderliness. 39.3\% of millennial tourists were between 17-28 age category and the majority of the respondents were between the ages of 28-37. It depicts that the tendency of elderly millennial tourists' arrival to Kandy is higher than the millennial that were born in between 1990-2000. This further implies that their expectations within a tourist destination may differ from the other age group.

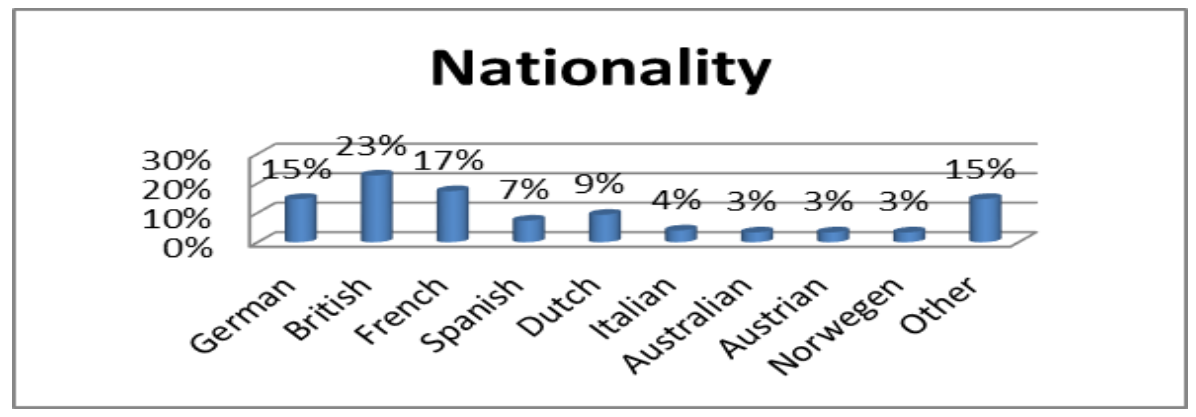

Figure 4.3: Nationality Distribution

Source: Survey data (2018)

The primary data was based on the nationality of millennial interviewees. However, as millennial respondents were widely distributed in 15 countries. United Kingdom was the dominating country obtaining the highest percentage (23\%) whilst, France $(17 \%)$ and Germany $(15 \%)$ become 2nd and 3rd places respectively. They have been followed by Netherlands (9\%), Spain (7\%), and Italy (4\%), whilst Australia, Norway and Austria take the same place obtaining three percent $(3 \%)$. 


\subsection{Objective Justification 01}

This is actually the imagination of Kandy city's expectation to be experienced before their arrival. In the questionnaire, it was used the 5-point Likert scale, from value "5" to "very important" till value "1" to "not important". The mean values and the standard deviation values of each of the ten important city destination attributes were obtained by the support of SPSS, and summarized them in Table 4.1.

Table 4.1: Descriptive statistics according to importance

\begin{tabular}{lccc}
\hline & Mean & $\begin{array}{c}\text { Std. } \\
\text { Deviation }\end{array}$ & $\mathrm{N}$ \\
\cline { 2 - 4 } Landscape \& scenic beauty & 4.01 & .934 & 150 \\
\hline Cultural \& history & 4.13 & .992 & 150 \\
\hline Entertainment & 2.59 & 1.291 & 150 \\
\hline Services & 3.12 & 1.237 & 150 \\
\hline Accessibility & 3.50 & .968 & 150 \\
\hline Safety & 3.93 & .920 & 150 \\
\hline Relaxation & 3.54 & 1.235 & 150 \\
\hline Climate & 3.77 & .977 & 150 \\
\hline Price & 3.37 & .973 & 150
\end{tabular}

Source: Survey data (2018)

According to the highest mean ranking (4.13) of destination attributes, the Culture and history can be identified as the most important aspect to visit Kandy city in order to gain knowledge of the culture and History of the destination. More comprehensively, it reveals that the religion aspect also included in this importance level. Kandy city's Landscape and scenic beauty has become the second important attribute to visit Kandy city. The safety within the destination is also important to millennial than climatic preferences. Any way the climate has become the fourth important position in millennial mind when arriving to Kandy city. The next importance level has taken the facilitation aspect for their stay in Kandy city. It categorizes Relaxation and good services and best prices to stay comfortably within the destination. But in Kandy city, the entertainment and night life has taken less important level of millennial' mind. As the results shows, out of 150 millennial respondents, exactly hundred (100) respondents have mentioned that they had a specific destination in their mind to visit before arrival to Kandy. Out of these hundred answers, forty-four (44) said they came to see Sacred Temple of Tooth relic, seven (7) for Cultural dance event, and five (5) for Esala procession. Altogether, fifty-six millennial have freely mentioned the cultural and historical attractions as their expectations to visit Kandy city. Few of millennial respondents had mentioned that to enjoy the fresh air and rainy climate in Kandy city. Thus it can be concluded that the impotence level of each attributes may differ one to each other. As one of interviewees reveals;

"And, in the Temple (Temple of Tooth Relic), there are lot of tourists. It is full of tourists.

We have come here to enjoy the Perahara. Also the cultural show dancers are really

nice." (Personal Communication, Respondent 01)

There are some respondents who are staying more than 8 to 10 days at the destination. When the researcher questions about the reasons for staying many days, they have mentioned that accessibility to nearby attraction as the reason. 
"Yes, we overnight here for 10 nights. And also we visit all the nearby places staying here.

For some examples, Sigiriya, Dambulla, Nuwaraeliya, and all the places in the city."

(Personal Communication, Respondent 05)

It depicts that more specific attributes can be identified in the Kandy city, being the city as a central point, facilitate to travel another more places. Also it reveals that Kandy is the best destination for long stays. The easiness for entering to other destinations also deserves some level of importance when selecting a destination by millennial. Also the accommodation factor may be identified as a specific attractive attribute in Kandy city.

\subsection{Objective justification 02}

Research Objective 2 of the study is to evaluate the satisfaction level of each Kandy city's destination attributes in order to identify the main city attributes that attract international millennial to Kandy city.

Table 4.2: Descriptive Statistics of satisfaction

\begin{tabular}{lccc}
\hline & $\mathrm{N}$ & Mean & Std. Deviation \\
\hline Landscape \& scenic beauty & 150 & 4.19 & .841 \\
\hline Cultural \& history & 150 & 4.21 & .830 \\
\hline Entertainment & 150 & 2.81 & 1.137 \\
\hline Services & 150 & 3.53 & .888 \\
\hline Accessibility & 150 & 3.68 & .877 \\
\hline Safety & 150 & 4.02 & 1.184 \\
\hline Relaxation & 150 & 3.57 & .776 \\
\hline Climate & 150 & 4.04 & .856 \\
\hline Price & 150 & 3.79 & 1.038 \\
\hline Night life & 150 & 2.29 & \\
\hline Valid N (list wise) & 150 & & \\
\hline
\end{tabular}

Source: Survey data (2018)

According to the table 4.15 the sample respondents are generally being satisfied with the Sri Lankan tourism product. As the questionnaire distributed to the millennial visitors, it requested that to mention their satisfaction level according to the effect of pulling them to the Kandy city.

When referred to the overall impressions regarding the satisfaction attributes, all the attributes are surpassing the mean of being agreed with or satisfied with the attributes. Among them the highest mean value (4.21) is scored for culture and history attribute. It is obvious with the research results that the Kandy city is a prestigious religious and cultural center in the country and the last Kingdom of the dynasty. Concentrated on those facts, there is a higher cultural value for Kandy to visit for millennial tourists. As per one of interviewees (One couple of French friends);

\footnotetext{
"We are from France. When comparing to Colombo, Kandy is a quiet city. We wanted to learn the culture and history in Sri Lanka. We have a book. This book is Lonely Planet, give all the information. We selected Kandy city to see the culture and history. And, the cultural show in the temple was very nice. But the temple is full. We were not relaxed there. But we think Kandy is nice City" (Personal Communication, Respondent 14)
} 
Further, the impression of the tourists are being more satisfied with the landscape and scenic beauty of the Kandy city. Kandy city is intrinsic with favorable climatic conditions with a higher humidity which makes away the tropical features of the country and giving the tourists a pleasant experience. One of interviewee said;

"We were here for two nights and we both are 27 years old. We wanted to the landscape in Kandy city and Culture and history. The lake is very nice middle of the city. We were staying in a small house nearby Grand Kandyan hotel. I guess culture and history is the most satisfied factor in Kandy city. Yesterday was a rainy day but today is good. As a tourist it is different experience in Sri Lanka. Yes, we definitely will come to Kandy city again. If we have only 24 hours in next time, we will see the Lake, tooth temple, museum and this garden (Peradeniya Botanical Garden) again. Yes for us, the most important thing may be the temple. (Personal Communication. Respondent, 04)

The climate has become the third dominating factor attracting the millennial tourists to the Kandy city as an attractive destination attribute. The climate is more enriched by the landscape and scenic beauty of The Kandy city, as it becomes the second highest attractive destination attribute with 4.19 mean score. Further justification can be given as per one of German interviewee;

“....Kandy city is not so much full (crowded) like in Colombo. The best thing I feel in Kandy city is the climate." (Personal Communication, Respondent 15)

According to the mean ranking of ten destination attributes, safety and the price factors have become the fourth and fifth attractive rankings respectively. It reveals that, the millennial tourists are much safe in their personal perspective whilst being satisfied of the price, the goods and services are being provided to the Millennials in Kandy city.

At the interviews, the researcher always tried to ask an additional question to the interviewees who have told that they are preferred to come again to the Kandy city. The question was, "what will you see, what you will do in next time, if you would have only 24 hours in Kandy city?" One of the answers was as follows;

If I have 24 hour next time, May be in that day I don't sleep in that 24 hours.

I will see everything in Kandy. The people are very nice in Kandy. Before we come

to Kandy, we were in Negombo. But in Kandy, we are more relaxing. We are very

satisfied in Kandy city. We love this City. This is a nice city."

(Personal Communication, Respondent 08)

\section{Conclusion}

Destination attributes are very important for a destination to be successful in the tourism market. Hence ten destination attributes were identified based on literature and examined them to identify the importance of them to Kandy City. The analysis showed the significant level of importance of attributes and the most important attributes. As the major target of the research study, The Researcher had evaluated and identified important destination attributes of Kandy City according to the level of importance of each in millennial preference before their arrival. The attributes are identified as, culture and history, landscape \& scenic beauty, safety, climate, relaxation, accessibility, price, services, entertainment and night life

The researcher has also achieved the second objective, evaluating the satisfaction level of each Kandy city's destination attributes and identify the main city attributes that attract international millennial to Kandy city, the most satisfied attribute as (1) the history and culture of the destination, (2) landscape and scenic beauty as the second, (3) climate, (4) safety, (5) price, (6) relaxation and (7) services are the most satisfied attributes. However, authorities should consider to improve the lower mean value attributes to enrich the Kandy city as a 24 hour operating live city. 


\section{References}

Cloud burst marketing report (2016). (Online) http://www.cloudburstmarketing.ca

Crouch, G. I., \& Ritchie, J.R.B. (1999). Tourism, Competitiveness, and Societal prosperity. Journal of business research. 44: 137

Dann, G.M.S. (1981). Tourist Motivation: An Appraisal. Annals of Tourism Research. 8(2): 187219.

Davis, G.F., Yoo, M., \& Baker, W. E. (2000). The Small world of American Corporate Elite, 1982-2001. Strategic Organization. 1(3), 301-326.

Formica, S. (2000). Destination Attractiveness as a Function of Supply and Demand Interaction. (Online) http://www.scholar.lib.vt.edu/theses/available/etd

Gooroocchurn, N. \& Sugiyarto, G. (2003). Competitiveness Indicators in Travel and Tourism industry. (online)http://www.erc.ucy.ac.cy/eglish/conference2003/Guntur.pdf.

Hu, Y., \& Ritchie, B.J.R. (1993). Measuring Destination Attractiveness: A Contextual Approach. Journal of Travel Research 32(2):25-34.

Khirun, B. M. S. (2011). Destination Attributes that Attract International Tourists to Visit Pangkor Island. Master Thesis, University Teknologi, Malaysia.

Klenosky, D.B. (2002). The "Pull" of Tourism Destinations: Ameans-End Investigation. Journal of Travel Research. 40(2): 385-395.

Kotharie, C.R. (2009). Research methodology Methods and techniques 2nd Revised edition. New Age International publishers.

Martin, M.B.G. (2005), Weather, Climate, and Tourism- A Geographical Perspective. Annals of Tourism Research. 32(3): 571-591.

McKercher, B. (1998). The effect of market access on destination choice. Journal of Travel Research. 37(3): 3947.

Miller, J. (1997). Cultural Tourism Worthy of Note. Journal of Hotel \& Motel Management. 212(15): 7- 17.

Richards, G. (2001). The development of Cultural Tourism in Europe. CAB international publishing.

Richards, G. (2002), Tourism Attraction Systems: Exploring Cultural Behavior. Annals of Tourism Research. 29(4)

Rojek, C. (1997). Indexing, dragging and the social construction of tourist sights. In C.

Sekaran, U., \& Bougie, R. (2010) Research Methods for Business: A Skill Building Approach. (5th Ed.)

Shenker, O. (2001). Cultural Distance Revisited: Towards a more Rigorous Conceptualization and Measurement of Cultural Distance. Journal of international business studies. 32(3): 519-535

Smith, M.K. (2003). Issues in Cultural Tourism Studies. London: Routledge.

Sri Lanka Tourism Development Authority Annual report, (2015)

Sri Lanka Tourism Development Authority Annual report, (2018) 